\title{
A Concept and Implementation of Optimized Operations of Airport Surface Traffic
}

\author{
Yoon C. Jung ${ }^{*}$, Ty Hoang ${ }^{\dagger}$ Justin Montoya ${ }^{\ddagger}$ \\ NASA Ames Research Center, Moffett Field, California 94035 \\ Gautam Gupta $^{\S}$, Waqar Malik ${ }^{* *}$, and Leonard Tobias ${ }^{\dagger \dagger}$ \\ University of California, Santa Cruz, NASA Ames Research Center, Moffett Field, California 94035
}

\begin{abstract}
This paper presents a new concept of optimized surface operations at busy airports to improve the efficiency of taxi operations, as well as reduce environmental impacts. The suggested system architecture consists of the integration of two decoupled optimization algorithms. The Spot Release Planner provides sequence and timing advisories to tower controllers for releasing departure aircraft into the movement area to reduce taxi delay while achieving maximum throughput. The Runway Scheduler provides take-off sequence and arrival runway crossing sequence to the controllers to maximize the runway usage. The description of a prototype implementation of this integrated decision support tool for the airport control tower controllers is also provided. The prototype decision support tool was evaluated through a human-in-the-loop experiment, where both the Spot Release Planner and Runway Scheduler provided advisories to the Ground and Local Controllers. Initial results indicate the average number of stops made by each departure aircraft in the departure runway queue was reduced by more than half when the controllers were using the advisories, which resulted in reduced taxi times in the departure queue.
\end{abstract}

\section{Introduction}

A irports are often a capacity-limiting constraint for the rest of the national airspace system, adversely affecting both throughput and efficiency ${ }^{1,2}$. There are many contributing factors that make airports the bottleneck. Notionally, those factors can be divided into two categories depending on the nature of the factors: physical and operational. Physical limiting factors include the number of available gates, number of runways, or airport layout. Operational limiting factors cause inefficient operations mainly due to lack of coordination among players including air traffic service providers, airlines, and flight operators. An example of an operational limiting factor is when a departure aircraft is waiting in a runway departure queue and blocks the entire queue due to a miles-in-trail (MIT) restriction over the departure fix or a missed opportunity of Expected Departure Clearance Time (EDCT). The consequences of operational limiting factors can be as serious as physical factors in terms of operational costs to airlines and environmental impacts. These types of inefficient surface operations are common in today's operational environment. They arise when there are many aircraft scheduled to take-off within a short timeframe, and tower controllers are still relying on their manual skills to manage the traffic. New decision support capabilities will be required to assist Air Traffic Control Tower (ATCT or "Tower") controllers in managing and controlling surface traffic smoothly and most efficiently.

Recently, research organizations both in the United States and Europe have been focusing on the issues of inefficient airport surface operations and trying to develop new concepts and procedures, as well as supporting technologies to improve the capacity and efficiency of the airport system.

In Ref. 3, the runway system has been identified as a key constraint and major delay source, and it has been shown that departure analysis could lead to the determination of control points where the runway operations can be

\footnotetext{
* Aerospace Engineer, Aerospace High Density Operations Branch, MS210-6, AIAA Senior Member

${ }^{\dagger}$ Aerospace Engineer, Aerospace Simulation Research and Development Branch, MS210-6, AIAA Senior Member

* Aerospace Engineer, Systems Modeling and Optimization Branch, MS210-6, AIAA Member

$\S$ Associate Research Scientist, University of California, Santa Cruz, Moffett Field, CA.

** Associate Research Scientist, University of California, Santa Cruz, Moffett Field, CA.

${ }^{\dagger}$ Aerospace Research Scientist, University of California, Santa Cruz, Moffett Field, CA.
} 
affected. A conceptual design of a departure planner has been developed, composed of functional components based on a queuing model approach ${ }^{4}$, with each component providing an automation aid to optimize the operation corresponding to the control point (e.g., gate, ramp). A queuing model of surface operations for Boston Logan International Airport has also been developed and delay reduction via a gate holding control scheme was evaluated ${ }^{5}$. More recently, a framework of coordinated surface operations among gate, ramp, taxiway, and runways was developed $^{6}$; an optimization algorithm to schedule individual aircraft taxiing on a network of nodes and links was part of this framework. A comprehensive optimized taxi scheduler has also been developed ${ }^{7}$, which was later improved by adding detailed physical and operational constraints ${ }^{8}$. Taxi delay reductions compared to a taxi schedule based on the first-come-first-served (FCFS) method were then demonstrated. Efficient runway scheduling algorithms have also been developed with the objective of maximizing the throughput of runway operations while satisfying various constraints ${ }^{9,10}$.

In an attempt to evaluate new concepts and early technologies in the field, the Federal Aviation Administration (FAA) is currently evaluating the decision support tool (DST) developed based on the concept of the Collaborative Departure Queue Management (CDQM) at Memphis International Airport ${ }^{11}$. For this concept, the delay of any departure aircraft in the departure queue does not exceed the target maximum delay by metering departure aircraft into the taxi movement area through a collaborative decision making scheme. The objective of the tool is to deliver a strategic surface traffic plan that is relatively easy for the Tower controller to execute without significant changes in operational procedures.

In Europe, the German Aerospace Center (DLR) conducted a field evaluation of the European Airport Movement Management by an Advanced Surface Movement Guidance and Control System (A-SMGCS), Part 2 (EMMA2) $^{12}$, a prototype surface DST at Prague Airport in 2008, where the Departure Manager (DMAN) component provides both ATC and airlines with a target off-block time (TOBT) of individual departure aircraft to meet the operational criteria.

This paper presents a concept of optimized airport surface operations developed as part of NASA's surface optimization research. A design of the system architecture of this tool and individual components to support the concept is presented. Further, based on this concept a prototype DST is described. The tool could be used by Tower controllers to improve the efficiency of airport surface operations as well as to reduce environmental impacts. Initial results of the human-in-the-loop (HITL) simulation for testing the tool and validating the concept are also presented. The organization of this paper is as follows. First, background information with a focus on current airport surface operations is presented. Next, an overview of the approach, objectives, assumptions, and requirements used in developing the surface concept are briefly described. Then, a brief description of the system architecture and optimization scheduler components developed to support the concept is provided. Finally, some of initial results obtained from real-time simulations that show the performance of the integrated system are presented. The paper ends with conclusions and future research plans.

\section{Background}

The domain of interest here is the surface of an airport, including the ramps, taxiways, and runways. Figure 1 illustrates an airport surface layout.

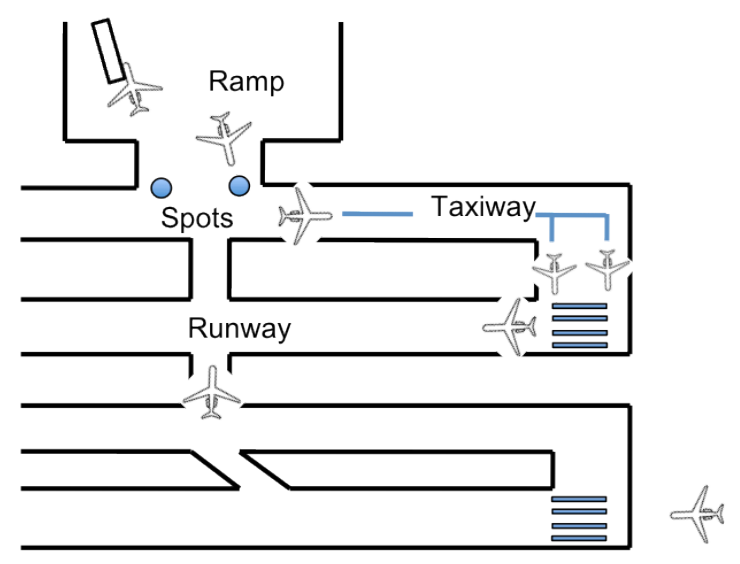

Figure 1: Airport surface layout 
Typical operations in the ramp area include passenger deplaning/boarding, refueling, food catering, and loading/unloading passenger luggage. Ramp Controllers control the push back of aircraft from the gate as the aircraft are ready for departure. Aircraft movement on taxiways and runways are strictly controlled by the Ground and Local Controllers working in a Tower. When an aircraft reaches the "Spot" ("spot" hereinafter), the Ground Controller provides a taxi instruction to the pilot and clears the aircraft for taxi into the "movement area" (area under FAA Tower control). The Ground Controller directs traffic on the surface and delivers departure aircraft to the assigned runways safely and efficiently, and arrival aircraft are directed from the runway to a spot (or a gate) safely and efficiently. The responsibility of a Local Controller is to manage runway operations, including take-off, landing, and runway crossing. During busy periods, there may be a queue of departure aircraft formed near the runway. The Local Controller determines the take-off sequence (e.g., first-come, first-served) and clears aircraft for take-off based on the rules of wake separation and other separation criteria applied to the aircraft. The entire sequence of departure runway operations mentioned above involves the following decision factors from the perspective of the Tower controller:

- Time to enter the taxiway from the spot.

- Taxi route, along with separation among aircraft on the taxiway and prioritization at intersections.

- Queue assignment - a queue area can have more than one lane (as shown in Fig. 1). In this case, assignment of aircraft to an appropriate queue lane needs to be decided.

- Time for take-off - clearance times should consider wake separation, RNAV (Area Navigation) procedures, arrival rates over departure fix, runway crossing of arrival flights, and other factors.

- Time for active runway crossing.

The purpose of the DST described in this paper is to provide both strategic and tactical advisories to the controllers in their tasks of managing and controlling traffic on the airport surface, so that the overall traffic becomes more efficient and environmentally sound. In current operations, most of the above decisions are made 'on-the-fly' by the controllers, and are based on heuristics as well as controller experience. It is possible that with increasing traffic, the above mentioned on-the-fly decisions and simple rules need to be augmented with DSTs to assist in these decisionmaking tasks. Further, with the anticipation of more automation in the future, there is a need to model the above decision-making processes that would satisfy multiple objectives, like reducing delay as well as environmental impacts. Past and on-going research addresses some aspects of the entire decision making process ${ }^{4,6-10}$.

\section{Concept of Optimized Surface Operations}

Two sub-problems are identified based on the idea of control points, observation of airport surface operations, and current roles and responsibilities of both Tower controllers and system users (i.e., airlines and airports): (1) release of aircraft from the ramp area into the taxiway; (2) runway operations for both take-offs and runway crossings. The scheduler functions for each sub-problem are the Spot Release Planner (SRP), and the Runway Scheduler (RS). Figure 2 shows the illustration of the areas of operation for each surface scheduler function. The detailed description of each scheduler/planner is presented in the following sections.

\# "Spot" is the hand-off point between the airline ramp control and Tower control, marked on the pavement with a number. 


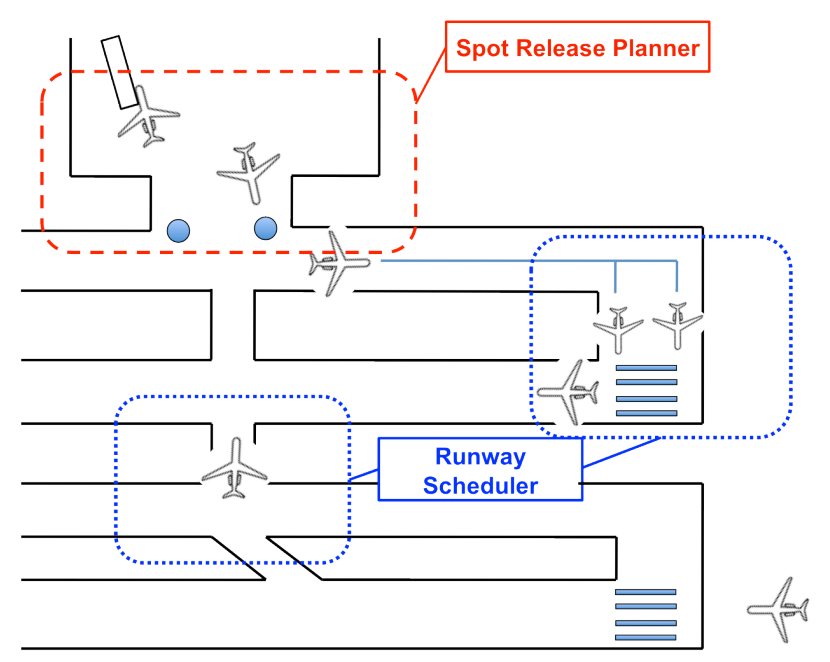

Figure 2: Areas of Operations of Surface Scheduling Algorithms

The concept of SRP can be implemented as a DST for the Ground Controller. For example, SRP can provide the Ground Controller with the sequence and timing advisories for each departure aircraft waiting at the spot for a taxi clearance. The concept of RS can be implemented as a separate DST for the Local Controller with no change in the current tasks assigned between the Local and Ground Controller. The RS can provide the Local Controller with the take-off advisory for departure aircraft and runway crossing sequence advisory for arrival aircraft. The detailed description of an implementation example is presented in Section IV.

\section{A. Assumptions and Requirements}

A framework of any concept is built upon assumptions and requirements, which are closely related to its implementation time frame. It frames the solutions based around estimates of available technologies including those associated with surveillance, avionics, and traffic demands. For the concept described here, the following assumptions are made:

- Ramp area operations are managed by airlines or airport authorities and, therefore, ATCT does not have direct control of gate push back for departure aircraft.

- The Ground Controller has authority to hold departure aircraft at spots within a specified time interval before the aircraft are cleared to move into taxiways.

- Voice is still the main means of communication between ATCT controllers and pilots.

The technology requirements are as follows.

- Aircraft position data are available in the ramp area through a surface surveillance system.

- Prediction of push back times of departure aircraft is available.

- Prediction of arrival times of departure aircraft at runway queue entrance is available.

- Prediction of arrival times of landing aircraft at runway crossing queue is available.

- Execution of algorithms should be fast enough to support real-time decision capabilities.

The first and second technology requirements are to provide to the decision support system the arrival-time prediction for departure aircraft. While it may sound desirable to have a surveillance system that provides a complete coverage of the ramp area, it will require significant infrastructure investment to airlines or airport authorities. As an alternative solution, participating airlines or airports can provide required data (e.g., flight status) to the decision support system with a data exchange system established.

\section{B. Technical Approach: Unified Models and Integrated Solutions}

The technical approach to model the decision process is based on a mathematical framework of optimization. The most optimal solution method would be to consider all the decision factors within the same framework, since there are interdependencies among them. For example, consider the clearance for entering the taxiway from the spot: aircraft bound for an over-subscribed departure fix could be held back at the spot so that taxiways and/or runway queues are not crowded. Clearly, this would change the structure of runway queues and today's typical operations. Addressing all the interdependencies in a single framework is a key to a globally optimal solution, and for this reason unified models for a given time horizon have been developed ${ }^{7,8}$. 
However, dividing the entire problem into parts, solving each part separately, and then integrating these solutions has significant advantages over the unified models approach. Some of these advantages are:

- A unified model that solves a larger problem suffers from increased computational times.

- Many optimization models solve the problem over a limited time horizon, with uncertainty being handled through various rolling horizon schemes. Large deviations from the plan would require quick recalculation, which might be easier in integrated solutions, especially when only a sub-problem would require recalculation.

- An integrated approach allows for exploring alternative combinations of sub-problem models through simulations, and will help in identifying critical areas of decision-making, resulting in maximum benefit with minimal changes. Sub-problems or models addressing these critical areas alone would provide good results with minimal alterations from current operations.

Given the relative merits of integrated and unified approaches, the concept presented here is based on an integrated approach of separate algorithms. With the high degree of uncertainty in prediction and control of aircraft, frequent recalculation becomes necessary and hence integrated approaches would perform well.

\section{Core Scheduling Models}

Based on the above discussion, the two sub-problems (schedulers) are now described, elaborating on their objectives, inputs, outputs, and pertinent implementation details. Each scheduler is formulated as a deterministic optimization problem with different objective functions and decision variables.

\section{Spot Release Planner (SRP)}

The objective of SRP is to generate an optimal schedule for aircraft release from spot to achieve maximum runway throughput by minimizing the makespan of the departure flights (i.e., time difference between the first and last takeoffs) in the planning horizon ${ }^{13}$. The inputs for SRP are:

- Estimated spot arrival times of departing aircraft

- Spot and assigned runway for each aircraft. This information is used to predict the nominal route to be used by the aircraft

- Type (or weight class) of each aircraft to be scheduled, along with required wake vortex separation criteria for take-off for each weight class

- Other separation criteria, e.g., MIT restrictions applied to aircraft pairs flying over the same departure fix

- Approximate taxi time for each departing aircraft

- Time window of intended take-off for departing aircraft. This information is required for meeting EDCT times for flights under a Ground Delay Program (GDP), or any other time constraints.

- Parameters for running SRP, such as a rolling planning horizon, which could include overlap times and a discounting scheme, if applicable

The SRP provides the following outputs:

- Optimum sequence of spot release

- Approximate release times

The SRP operates at two different planning horizons: SRP long term (SRP-LT) and SRP short term (SRP-ST), and the motivations and benefits of this scheme are:

- SRP-LT calculates the optimal spot release schedule for aircraft that are scheduled to push back and reach the spot approximately an hour in the future with a planning horizon of 15 minutes. The larger look ahead time allows for certain collaborative decision-making between ATC and airlines, such as gate push back and ramp area control in coordination with arriving aircraft.

- SRP-ST works in the immediate time window of up to 15 minutes and accounts for any uncertainty in the airline schedule, ramp operations, etc. The fast running-time of the algorithm allows for updates (as required) of spot release times based on new estimates of spot arrival times provided either by the tool or direct updates from the airline.

The objective and most of the inputs for the two models will be the same. Offline testing conducted by the authors showed an average improvement of $8-15 \%$ in overall runway throughput compared with the results from the system without SRP for a simple case with 20 aircraft in a 15-minute planning horizon. Detailed descriptions of the algorithm and test results are found in Ref. 16. 
The SRP has the following benefit mechanism:

- It provides a mechanism for delaying the aircraft at the spot rather than at the departure queues, resulting in less congested surface traffic without sacrificing runway throughput. In addition, average taxi time in the movement area can be reduced because aircraft would taxi at slightly higher taxi speeds with less stop-and-go situations. This relates directly to fuel saving and less emissions and noise to the environment.

- Its data can facilitate collaborative decision-making on gate push back for departures with airlines, and with Air Route Traffic Control Center (ARTCC) and/or Terminal Radar Approach Control (TRACON) facilities for arrival aircraft.

- It provides a hypothetical maximum throughput that can be used as an upper bound for other schedulers, resulting in an increase of computational efficiency.

\section{Runway Scheduler (RS)}

The RS manages the operations of a single departure runway, scheduling take-offs as well as runway crossings for arrival aircraft. The scheduler must satisfy constraints, such as wake separation criteria, MIT restrictions, and EDCTs. Different optimization problems can be formulated based on the objectives of optimization. A few candidate objectives are as follows:

- Minimize system delay by minimizing time spent by all aircraft in the queuing area in a given planning horizon

- Minimize the maximum delay spent by any aircraft in the queue (i.e., a fairness objective)

- Maximize runway throughput by minimizing the departure time of the last aircraft in the departure sequence

The optimal schedules in the above three cases may not be the same. Identification of the preferred objective would require trade studies, inputs from the system users (e.g., airlines), air navigation service providers (e.g., controllers), and environmental considerations. Various optimization formulations for RS have been developed using a Mixed Integer Linear Program as well as Dynamic Programming, and performance evaluated for various traffic levels at DFW ${ }^{9,10,14}$. The analysis results indicate that system delay was a better objective than two other objectives?.

The RS solves the deterministic problem for a given planning horizon, and handles uncertainties during successive runs by a rolling planning horizon. The inputs for the runway scheduler are:

- Configuration of departure queues (i.e., number of queue lanes and usage)

- Weight class of each departure aircraft

- Separation criteria for departure aircraft

- Any constraints on usage of queue

- Runway queue entry time for each aircraft

- Individual time windows of intended take-off for departing aircraft

- Time windows of arrival aircraft for runway crossing

The RS provides the following outputs:

- Runway queue assignment for each departure aircraft

- Sequence and timing for take-offs for each aircraft

- Sequence and timing of active runway crossing

- Runway exit assignment for arriving aircraft when applicable

The RS can provide the Local Controller with the take-off and runway crossing sequence advisories. In addition, a runway queue assignment advisory may be added. However, the timing advisory for take-off and runway crossing operations is not likely a candidate for a near-term capability due to various uncertainties in taxi operations. Since RS provides an additional decision for each departure aircraft (i.e., which queue to join in the case when multiple queue lanes are available), the communication between the pilots and the controller may be slightly increased. However, the controller is not likely to be required to communicate with multiple aircraft at the same time since such controls are sequential in nature. Runway queue entry times can be provided by a separate taxi scheduler (when available) or by a simple trajectory prediction function of the tool based on surface surveillance data. Similarly, runway exit suggestions can also be communicated to the pilot over voice.

\section{Implementation and Testing of Surface Models for Decision Support Capabilities}

This section provides a brief description regarding implementation and testing of the surface models described above in order to create decision support capabilities for the Tower controllers.

6

American Institute of Aeronautics and Astronautics 


\section{A. An Implementation Example}

As an initial attempt at an early implementation, both SRP (only the SRP-ST) and RS algorithms were integrated within the Surface Management System (SMS) ${ }^{15}$. SMS was originally developed as a DST to assist ATCT controllers and managers as well as airline operators in managing and controlling airport surface operations ${ }^{16}$. It was modified to a real-time, HITL surface simulation platform. SMS was configured to receive aircraft position data generated by the Airspace Traffic Generator (ATG) ${ }^{17}$. ATG is a high-fidelity, real-time aircraft simulation tool that provides the capability to move the aircraft on the airport surface via keyboard entries by pseudo-pilots, and generate and display targets of the aircraft. ATCT controllers were in voice communication with the pseudo-pilots through a digital audio system. Figure 3 illustrates the system architecture of the integrated SMS-ATG simulation platform.

Software modules of SRP and RS were developed and interfaced with SMS. SMS calls the scheduler modules running at a time interval (e.g., 40 seconds). SMS provides the SRP module with aircraft position data and estimated arrival times of departure aircraft at their designated spots. Then, the SRP module computes and sends the optimum release sequence and time-window of each departure aircraft within the next planning time horizon (e.g., 15 minutes) back to SMS. Similarly, SMS Model provides estimated arrival times of departure aircraft at the runway queue entry, and the prediction of arrival aircraft's times at the runway crossing queue. The RS module calculates the optimal sequence of take-offs and arrival runway crossings. The advisories are displayed on the window of the SMS map display.

As an initial test of system integration, surface operations on the east side of DFW was simulated in December 2009, and a basic check of functionality of the SRP and the Graphical User Interface for Tower controllers was conducted. In April 2010, complete DFW east side operations using all of east side terminals were simulated and data were collected to analyze algorithm performance, human factors issues, and usability of decision support features. Baseline scenarios were generated using actual DFW airport surface traffic, and high demand traffic scenarios were created by scaling up the baseline scenarios.

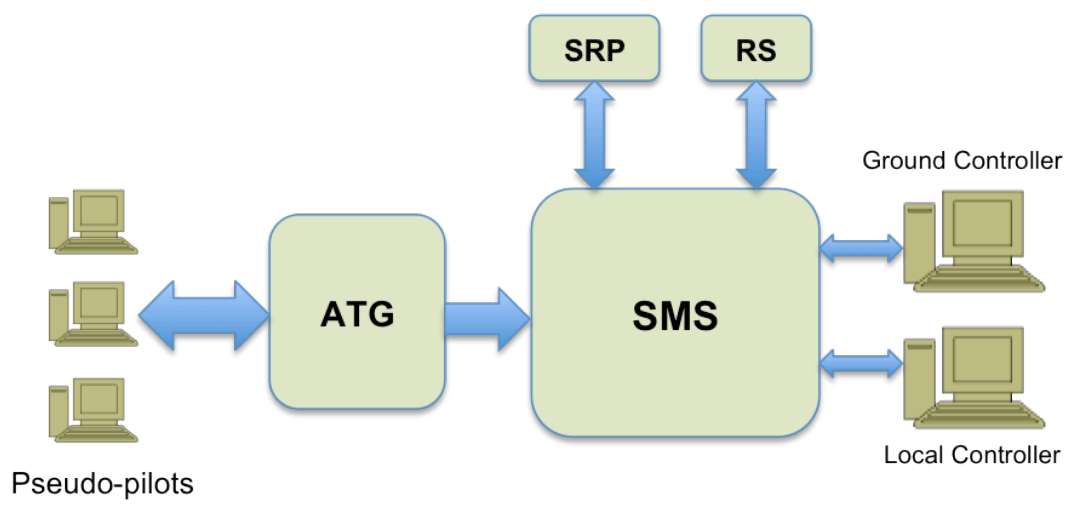

Figure 3: System architecture of the integrated SMS-ATG simulation platform

\section{B. User Interface}

Multiple user interfaces to provide the spot release sequence and timing advisories to the Ground Controller, and runway sequence advisories to the Local Controller, were developed and evaluated though the experiment. Both advisories were displayed on the SMS map display. Two types of advisory displays were evaluated: a data-tag option and a timeline option. The data-tag advisory option for SRP displays departure sequence and timing information on the data block of an aircraft inside the ramp area. The timeline advisory option for SRP displays the aircraft callsigns, departure fix, and spot numbers on a timeline. For the RS advisory, the timeline advisory option displays the sequence of runway operations in a stack of aircraft callsigns ordered by their departure times. Departure aircraft and arrival aircraft for runway crossing are distinguished by color (departure: green, arrival: white). Figures 4 and 5 show screen images of SRP and RS advisories. The data block of flight COA6306 indicates the release sequence is 1 and the aircraft needs to be released within 15 seconds from spot 33 . 

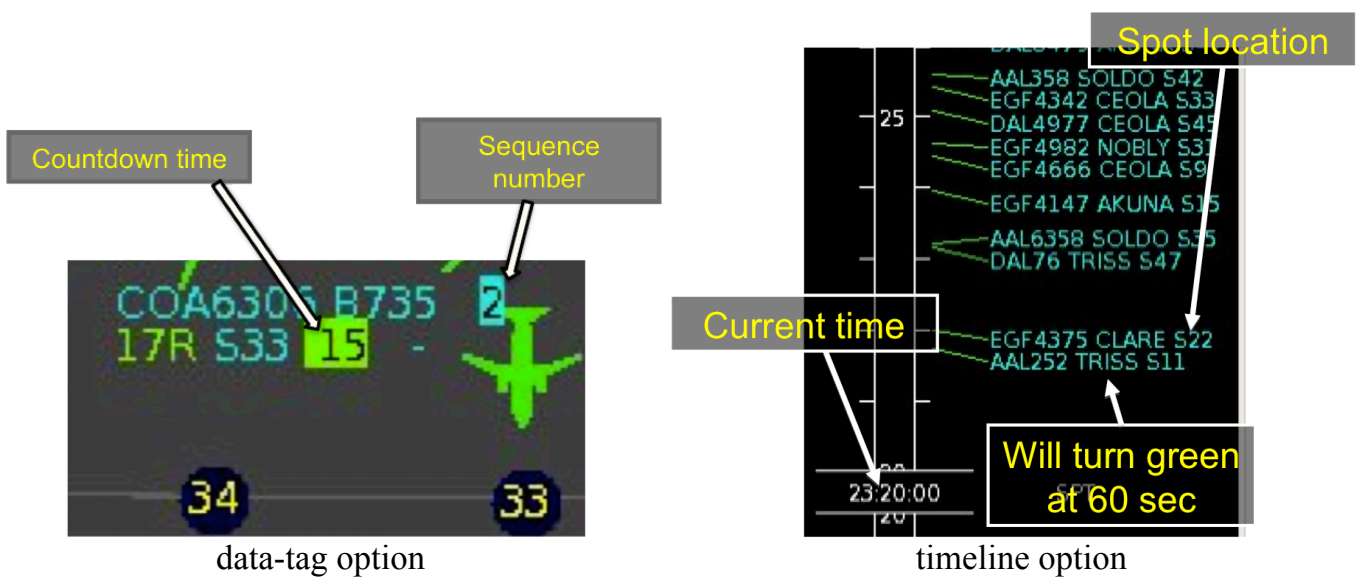

Figure 4: SRP advisories for the Ground Controller for the data-tag option and timeline option

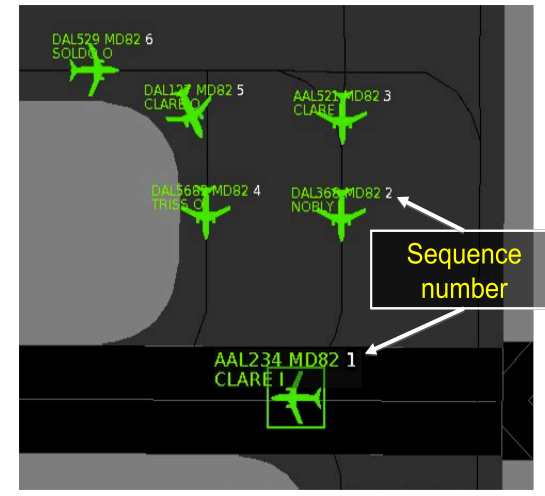

data-tag option

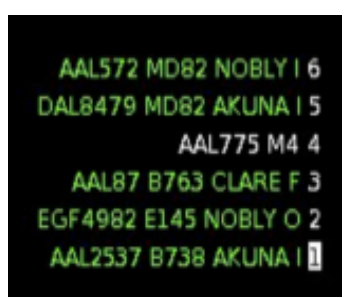

timeline option

Figure 5: RS advisories for the Local Controller for the data-tag option and timeline option

\section{Results}

This section presents initial results obtained from the real-time simulation completed from April to May 2010, showing the efficiency performance of the integrated system. Results related to user interface are not discussed here. They will be the subject of a separate report. Multiple test scenarios, including normal and heavy-traffic scenarios, were created based on the actual DFW surface traffic data collected in 2008. The heavy-traffic scenarios included 65 departures and the same number of arrivals in 45 minutes. For each traffic scenario, three advisory options were tested: timeline, data-tag, and no advisory. Two retired controllers with over 20 years of experience at DFW participated as Ground and Local Controllers in the experiment, rotating the position for each scenario run.

Both system performance, measured by the metrics including average taxi delays, number of stops, and departure queue size, and human factors data were collected from each run. The system performance data were recorded in SMS log files and ATG log files. For example, SMS log files contain aircraft position data as well as the outputs of the algorithms. The metrics to evaluate the performance of the algorithms included total taxi time, average taxi time, taxi delay, departure runway queue size, arrival crossing queue size, fuel consumption, and emissions. Controllers' inputs either by mouse click or keyboard entry, were also recorded in the SMS log file. At the end of each run, a questionnaire was administered to the controllers to collect workload and situation awareness data.

The data collected from the experiment were partially analyzed (6 out of 52 simulation runs were analyzed) to obtain initial results. Initial results for the average number of stops made by each departure aircraft as well as associated stop time are shown. Figure 6 shows the average number of total stops made by each aircraft during taxi between push back from the gate and take-off from the departure runway. The results show that the total average number of stops was reduced from 7.3 to 4.4 when advisories were provided to the controllers using either the datatag or timeline option. Figure 7 shows the distribution of stops in the ramp area and the departure queue area. The average number of stops per aircraft in the queue area was reduced to more than half (i.e., 5.4 vs. 2.2) when advisory 
options were used using either the data-tag or timeline option. The number of stops in the ramp area revealed an opposite trend although the differences between the results with and without advisories were small (i.e., 1.6 vs. 2.1). The trend was consistent across both controllers. These preliminary results indicated the overall taxi performance of departure flights was improved by providing advisories to the controllers when they released aircraft from spots as well as sequence departure aircraft for take-off. The average stop times in the queue and ramp area revealed the same trend (Fig. 8). The average stop time per aircraft in the departure queue was reduced from 271 seconds to 119 seconds when advisories were used. In the ramp area, however, the average stop time was increased from 29 seconds to 159 seconds, which indicates that holding of departure aircraft at spots has shifted delay from departure queue to the ramp area. This was due to the intended design of the architecture where departure metering starts at the spots instead of gates. This issue can be resolved by the SRP-LT approach proposed in this paper.

\section{Departure Total Stops}

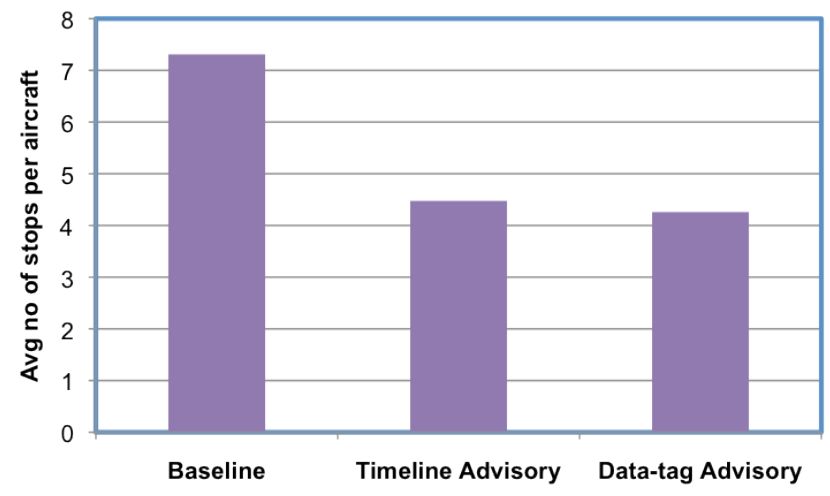

Figure 6. Average number of stops made by each departure aircraft for the entire taxi operation (a heavy traffic scenario).
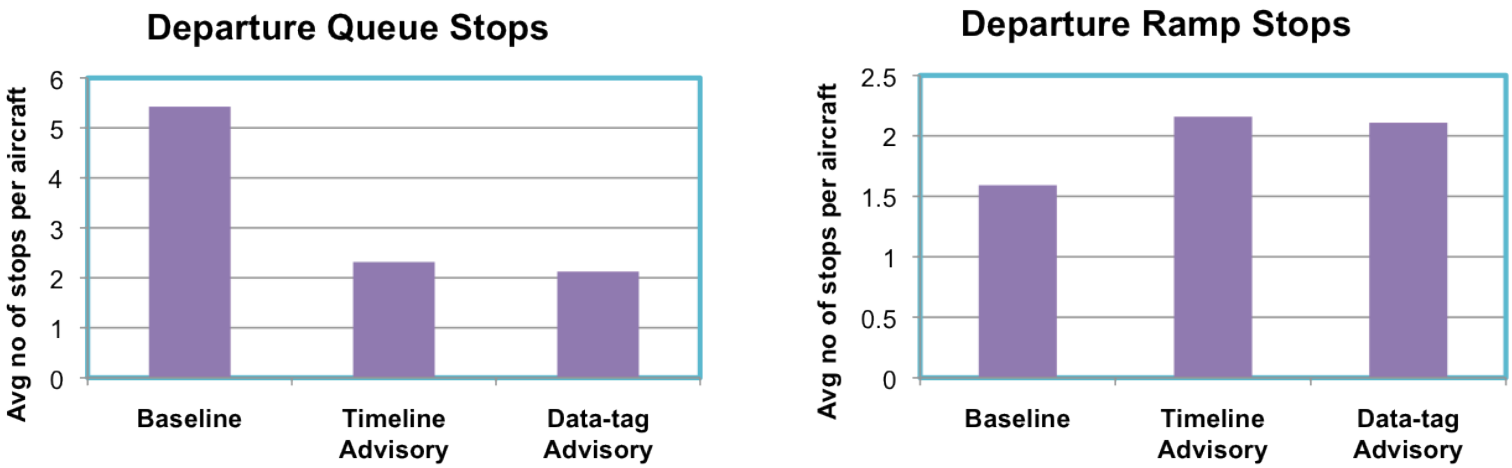

Figure 7. Average number of stops made by each departure aircraft in runway queue and ramp area (a heavy traffic scenario). 
Departure Queue Stop Time

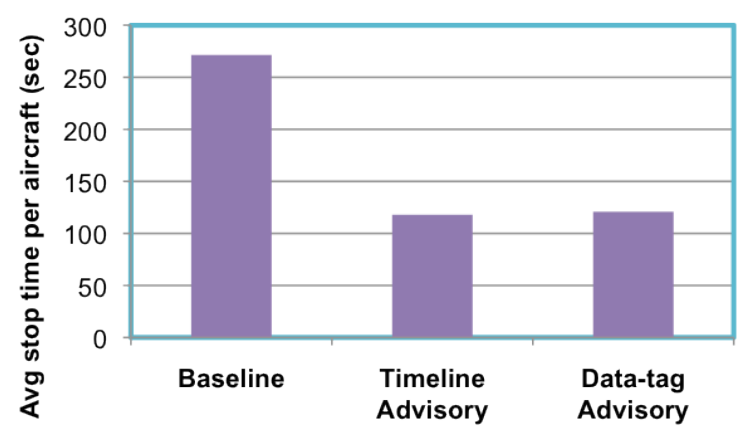

Departure Ramp Stop Time

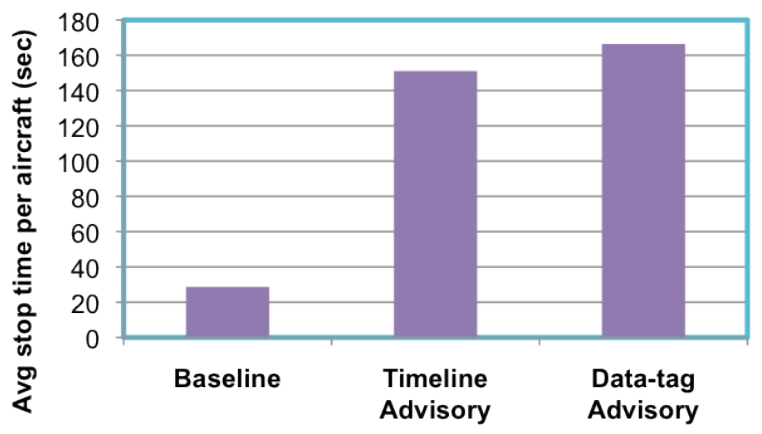

Figure 8. Average stop time by each departure aircraft in runway queue and ramp area (a heavy traffic scenario).

\section{Conclusions}

The focus of this surface optimization research has been on the development of a concept and procedures that would improve the overall efficiency of surface operations with less environmental impact. This paper presents a concept of optimized operations for airport surface traffic developed by the researchers at NASA Ames Research Center. The concept hinges on an integrated framework of optimized surface operations by integrating individual optimization scheduling models that represent sub-problems of airport surface operations. Two main models were proposed: Spot Release Planner and the Runway Scheduler. The integrated framework built upon these two models allows overlaps between each model, which can be advantageous over a "unified" approach in terms of robustness against uncertainties as well as computational performance. In a unified solution approach, an optimized taxi scheduler solves for every individual aircraft's taxi schedule on the entire airport surface, between gates and runways, in a large complex problem.

An example of a prototype implementation and testing of a decision support tool for the air traffic control tower controllers was presented. A software module for the spot release planner algorithm was developed and integrated with the Surface Management System. In doing so, the Surface Management System was modified to be used as a real-time, human-in-the-loop simulation platform. The surface scheduling algorithms were evaluated through a human-in-the-loop experiment, where both Spot Release Planner and Runway Scheduler provided advisories to the Ground and Local Controllers. Initial results indicated the average number of stops made by each departure aircraft in the departure runway queue was substantially reduced when the controllers used the advisories. By design, the corresponding average stop time by the aircraft in the queue was also reduced.

\section{Future Research}

Future research and development efforts will include: 1) improve the robustness of algorithms to uncertainties, such as delay in controller/pilot response, variation in aircraft taxi speed, and errors in aircraft trajectory prediction or surveillance system, 2) develop features as a decision support tool by providing "controls" to change the characteristics of the system depending on the traffic situation or the controller preference, and 3) improve user interfaces to enhance usability of the tool.

Another future research area could be to explore the practical methods using the unified approach mentioned above. The model, simply called a taxi scheduler, could solve a traffic-scheduling problem that would cover the entire airport surface, which is equivalent to a combined SRP-RS system. The merit of such scheduler is the ability to include both arrivals and departures in the optimization model, and solutions are expected to be more accurate than the solutions from the integrated approach. Similar advisories as those from the integrated SRP-RS system can be provided to the Tower controllers.

\section{References}

${ }^{1}$ S. Zelinkski and T. Romer, "An Airspace Concept Evaluation System Characterization of National Airspace System Delay," AIAA 4th Aviation Technology, Integration and Operations (ATIO), September 2004. 
${ }^{2}$ Mueller E.R. and Chatterji G.B., "Analysis of Arrival and Departure Delay Characteristics," AIAA Aircraft Technology, Integration, and Operations (ATIO) Forum, Los Angeles, CA, October 1-3, 2002.

${ }^{3}$ Idris, H., Delcaire, B., Anagnostakis, I., Hall, W., Pujet, N., Feron, E., Hansman, R., Clarke, J., and Odoni, A. "Identification of Flow Constraint and Control Points in Departure Operations at Airport Systems," AIAA Guidance, Navigation, and Control Conference, Boston, MA, Aug. 10-12, 1998.

${ }^{4}$ Anagnostakis, I., Idris, H., Clarke, J., Feron, E., Hansman, R., Odoni, A., and Hall, W. "A Conceptual Design of a Departure Planner Decision Aid," 3rd FAA/Eurocontrol International Air Traffic Management $R$ \& D seminar, ATM-2000. Naples, Italy, 2000.

${ }^{5}$ Pujet, N., and Feron, E. "Input-Output Modeling and Control of the Departure Process of Congested Airports," Air Traffic Control Quarterly Vol. 8, No. 1, 2000, pp. 1-32

${ }^{6}$ Balakrishnan, H., and Yoon, J. "A Framework for Coordinated Surface Operations Planning at Dallas-Fort Worth International Airport," AIAA Guidance, Navigation, and Control Conference, Hilton Head, SC, United states, August 20, 2007 - August 23, 2007.

${ }^{7}$ Smeltink, J., Soomer, M., de Waal, P., and Van Der Mei, R. "An Optimisation Model for Airport Taxi Scheduling," Thirtieth Conference on the Mathematics of Operations Research, Lunteren, The Netherlands, January 2005.

${ }^{8}$ Rathinam, S., Montoya, J., and Jung, Y. "An Optimization Model for Reducing Aircraft Taxi Times at the Dallas Fort Worth International Airport," 26th International Congress of the Aeronautical Sciences (ICAS). Anchorage, Alaska, 2008, pp. 14-19.

${ }^{9}$ Gupta, G., Malik, W., and Jung, Y. C. "A Mixed Integer Linear Program for Airport Departure Scheduling," 9th AIAA Aviation Technology, Integration, and Operations Conference (ATIO), Hilton Head, South Carolina, September 21-23, 2009.

${ }^{10}$ Rathinam, S., Wood, Z., Sridhar, B., and Jung, Y. C. "A Generalized Dynamic Programming Approach for a Departure Scheduling Problem," AIAA Guidance, Navigation, and Control Conference, Chicago, Illinois, August 10-13, 2009.

${ }^{11}$ Brinton, C. "Field Test Results of Collaborative Departure Queue Management (Draft version)," 29th Digital Avionics Systems Conference, Salt Lake City, UT, USA, October 3-7, 2010.

${ }^{12}$ Biella, M. "European Airport Movement Management by A-SMGCS, Part 2 (EMMA2): Validation Test Plan PRG." 1 ed., Deutsches Zentrum für Luft und Raumfahrt (DLR), Braunschweig, Germany, 2010.

${ }^{13}$ Malik, W. A., Gupta, G., and Jung, Y. "Managing departure aircraft release for efficient airport surface operations," AIAA Guidance, Navigation, and Control Conference, Toronto, Canada, August 2-5, 2010.

${ }^{14}$ Gupta, G., Malik, W., and Jung, Y. "Incorporating Active Runway Crossings in Airport Departure Scheduling," AIAA Guidance, Navigation and Control Conference, Toronto, Canada, August 2-5, 2010.

${ }^{15}$ Raytheon. "CTO-05 Surface Management System, CTOD 24 Final Report." May, 2004.

${ }^{16}$ Atkins, S., Jung, Y., Brinton, C., Stell, L., Carniol, T., and Rogowski, S. "Surface Management System Field Trial Results," AIAA 4th Aviation Technology, Integration, and Operations Forum, Chicago, IL, United states, September 20- 23, 2004.

${ }^{17}$ SAIC, Airspace Traffic Generator, User’s Manual Supplement, Revision 2.6, December 2006. 